\title{
Manufacturing in Networks - Competitive Advantages for Virtual Enterprises
}

\author{
Prof.-Dr. Engelbert Westkämper \\ Dipl.-Ing. Dipl. Wirt.-Ing. Hans-Jörg Tutsch \\ Fraunhofer Inst. f. Manuf. Engineering and Automation (IPA) \\ Nobelstr. 12, D-70569 Stuttgart, Phone: +49 711970 1100, \\ Fax: +497119701102
}

\begin{abstract}
Typical aspects of global competition are the regionally different production factors and varying demands on product function, quality and performance. Success is not only a matter of consistent market orientation but increasingly depends on regional contributions to production and employment. Crucial success factors are cooperation, the availability of components in a country, the use of the existing infrastructure, etc. Thus, many companies are building up international production capacities or shifting them to foreign regional markets to sell their products not only at home but also in international markets. They form global networks to which independent partners contribute their individual core competencies.

The following article describes approaches to activate performance potentials absolutely necessary in the global competition. Virtual enterprises allow a close-tothe-customer production together with extremely flexible capacities and short shipping times. Especially for SME this is a chance to participate in the global competition to their maximum advantage. This article shows the benefits of virtual enterprises. It describes the life cycle of a virtual enterprise dealing with key aspects from the creation to the management of such an organisation.
\end{abstract}

Keywords

Virtual enterprises, small and medium-sized enterprises, cooperating networks 


\section{FUTURE PROSPECTS OF SMALL AND MEDIUM-SIZED ENTERPRISES ON THE GLOBAL MARKET}

\subsection{Initial situation}

The challenge modern companies must tackle finds expression in the recognition that "the rapid reaction to customer demands is a pre-condition to survive among the competition".

In the global marketplaces the significance of competitive success factors is changing. Competitive aspects of the year 2005 include, for example,

- the supply of system solutions,

- logistic competence,

- computer data links to the customer,

- delivery time and reliability,

- flexible response to order amendments and

- supply of supporting services, such as technical consulting and after-sales service.

These changes and the global availability of products are influencing the behaviour of the customers and stimulating individual customer demands. As a consequence, the producing sector has to respond by an ever broader product range, while the service sector must offer a more customised service profile. Markets for individualised products or services are small and quickly saturated, so that product life cycles are shortened and service providers are forced to expand their service range continuously. In the shortest possible time, the producing sector develops new products with more sophisticated and extended functions in order to tap new markets. Cost leadership or a strategy to distinguish oneself from competitors must lead to new market shares to justify the increase in expenditure. Enterprises with the will to survive in spite of changing market requirements must excel their rivals in innovative power, quick learning capability and adaptability. Using global resources for development activities, purchase parts and components, as well as for production and logistics is a common strategy among manufacturers. Though small and medium-sized enterprises (SME) can particularly boast of flexibility and a high potential for innovation, they suffer from restrictions related to resources, for example insufficient market power and investment barriers. SMEs with a staff of up to 500 persons and a maximum in annual sales of DM 100 million account for $98 \%$ of all enterprises in Germany. Medium-sized businesses employ two thirds of Germany's labour force.

\subsection{The solution: building cooperations}

Government subsidies for business foundations as well as disincorporations by larger companies are leading to smaller units. Due to the "uneasy triangle" (i.e., simultaneous shortening of product life cycles, expansion of development and design cycles, and the explosion of preparation costs), enterprises find themselves 
caught in a "time trap". To escape from it they need to build cooperations and recombine their core competencies.

Possible forms of cooperation are groups, joint ventures, syndicates and strategic alliances. The first three types operate as corporated or incorporated firms, whereas strategic alliances usually enter into long-term cooperation agreements in a specific business area. A virtual enterprise, by contrast, combines various companies while maintaining the greatest flexibility and business independence. A crucial feature of a virtual enterprise is that it appears as a single company in the market though actually consisting of several enterprises. Thus, its internal relations resemble a decentralised enterprise.

\subsection{Obstacles to cooperations}

The current trend towards business take-overs and mergers all over the world makes it hard to believe what organisation experts predict. According to them, the future will make cooperating networks become a rule whereas large enterprises will be an exception. On the way to this, there are immense problems hampering the formation and functioning of virtual organisations. Obstacles are, for example, the widely held opinion not to delegate tasks, as well as the lack of any clear overall picture of the system (insular point of view). A lack of identification with network cooperations on "not-invented-here" grounds, and the fear of losing knowhow or one's independence, are factors counteracting the development of networks. In addition, many. SME fear to lose their present quality standard through their participation in a network. They believe that uniqueness is the only source of permanent competitive superiority and only achievable on one's own. Apart from that, quite a number of managerial and legal problems arise from the formation of networks - especially with regard to the distribution of profits or the division of losses in international networks, but also regarding copyrights and rights of ownership, laws of taxation and liability. Without confidence in potential network partners there is no interest in discovering joint win-win-situations. Besides, the partner companies may find it hard to see through the tricks of the network organisation and they often lack experience in order management and network control.

There are some crucial disadvantages for SME linked to current forms of VEs: they are either limited to one branch of industry or are only aligned towards a single product, or the cooperating enterprises form a closed and inaccessible circle.

The mentioned difficulties call for new ways of organising virtual enterprises.

\section{LIFETIME SUPPORT FOR VIRTUAL ENTERPRISES}

To enable the cooperation in networks, SME in industry as well as in the service sector require assistance during all stages of a virtual enterprise's life cycle. What kind of support the network initiators or participants actually need depends on the tasks the individual network has to fulfil. 


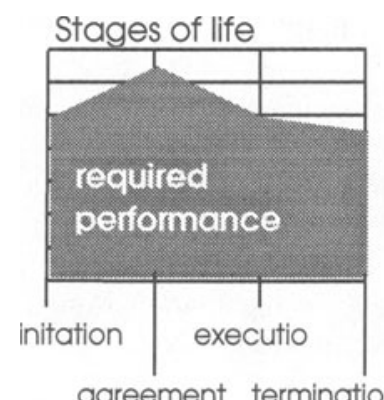

agreement termination

\section{Stage 1: Initiation and search for partners - contact and selection of potential partners}

\section{Stage 2: Agreements}

-strategic planning and implementation

\section{Stage 3: Execution \\ - order processing}

Stage 4: Termination or reconfiguration

- dissolution and distribution

Figure 1: Life cycle stages of a Virtual Enterprise.

A neutral service and management centre has to be established to serve this purpose - for example by the chambers of commerce - which acts as a broker providing the required services. Thus, a cooperation expert is created with a wide range of experience and know-how. It provides the core competencies for coordinating networks, that means cooperation management, project and consulting management, information and communication management, finance and administration. Accordingly, this service broker must bring together experts in all those fields, for example a cooperation manager, a consultant, an IT-expert and legal advisers.

This institution enables the network partners to focus on their core competencies. The companies are relieved of management tasks in the network and yet can be sure that these tasks are taken care of by a competent partner. The concentration on their competitive and renowned core competencies enables the network partners to outsource tasks or parts of the manufacturing process, where other providers are simply better or more cost-effective, and for which they have no capacities available.

Companies interested in the experiences and methodical approaches of the service centre will find this information accessible on commented Web pages. As a tele-broker the service centre provides a knowledge database and supports or consults the companies according to need. Another database contains offers and requests for cooperations. Moreover, the service centre arranges contacts to companies that were checked for their network suitability and attractiveness. Companies without this suitability check will be offered an entry in the electronic bulletin board to search for and establish contacts with interested partners. 


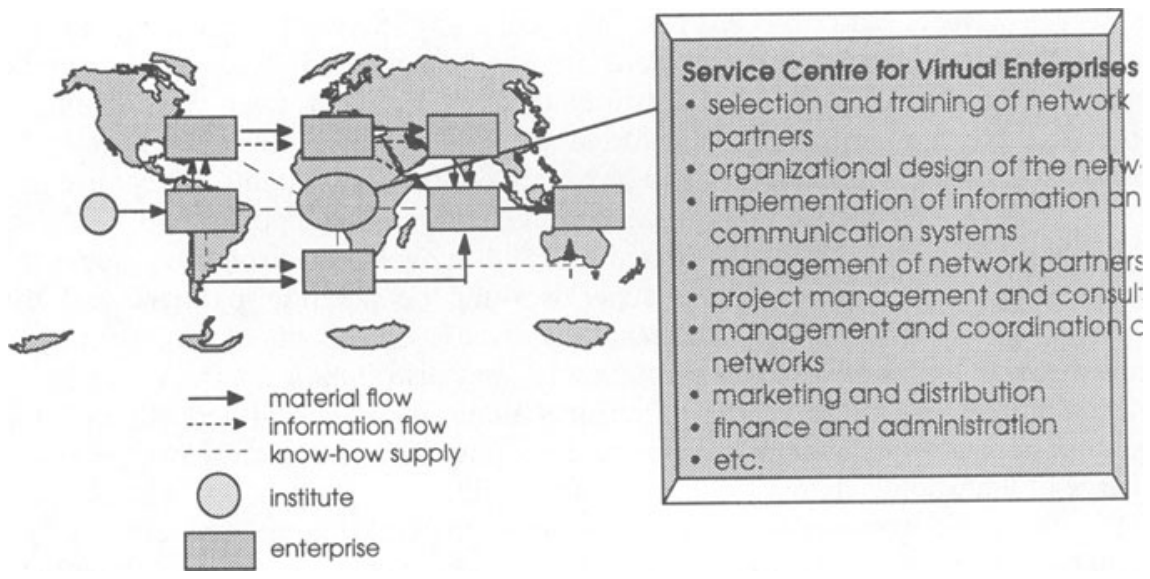

Figure 2: Network organisation

Planning a network's initiation, formation and organisation takes a lot of time, though the benefits are not predictable at the start. This is a problem especially for SME, where delegation is only practised on a small scale. During the initiation stage and search for partners the service centre helps to clear up issues of economic efficiency and feasibility. It stores the data gathered by quick-checkprogrammes about performance, flexibility and quality of potential partners, thus facilitating the assessment and selection of future partners. Furthermore, an experienced service centre is able to help with the description of network rules and the definition of necessary framework conditions, such as infrastructure, corporate targets and project volume. Besides, it can act as a mediator when it comes to conflicting interests among partners. If required, it handles the data on cooperation projects in demand or on offer and manages the knowledge about project execution. A data base is then set up and maintained, containing performance characteristics and, if possible, the current capacity utilisation of companies. Another important task is to adapt and harmonise the key processes of the partners and also the inter-company interfaces in order to minimise network friction and superfluous overheads. Thanks to its deep experience the service centre can speed up a network's creation, thus enabling a quicker order processing and fulfilment of customer requirements. From a neutral position, the service broker defines crosssectional functions with other companies and co-ordinates the integration of external service providers. Apart from that, it supports the network in obtaining a quality certification and in project canvassing, provided the network partners keep reporting their capacity surpluses. Moreover, the service centre's experience provides for innovative solutions, for example in information technology or business process optimisation.

At the agreements stage the service centre gives legal advice on contract drafting and assists in clearing up matters of liability and ownership, tax laws or issuing patents - subjects which are specifically complex with regard to networks. Another possible task of the service centre is to assign the jobs to the respective 
network partners and to configure the company network according to the requirements. In doing this, it resorts to standard network types, for example innovation networks, production networks or sales networks. Each type requires a specific kind of organisation and information flow. Standard networks have to be adapted to actual needs, but are already largely optimised through practical use and have proved a valuable help in quickly building and realising cooperations.

At the third stage of a virtual organisation's life cycle, the execution stage, the management centre controls and supervises the cooperation partners and the external service providers. On demand, it even assumes the complete project management, or takes on tasks in marketing and distribution areas. As a neutral mediator it helps to resolve target conflicts among network partners. In case the quality requirements among partners are diverging, the servicecentre can be put in charge of the whole network's quality management.

The network partners can also delegate network-internal orders to the management centre, for example in production planning, order scheduling, network-internal capacity allocation, order control and order tracking, performance and cost control. This makes the service centre a competent customer contact with regard to order progress and delivery time. Supporting a variety of networks, the service centre provides the network partners with synergy effects for supply markets or distribution. Being trained in exception handling the staff of an independent service centre offers helps with special cases like breakdowns or product modifications. Other functions, such as invoicing or attending to customers and external service providers, can also be carried out.

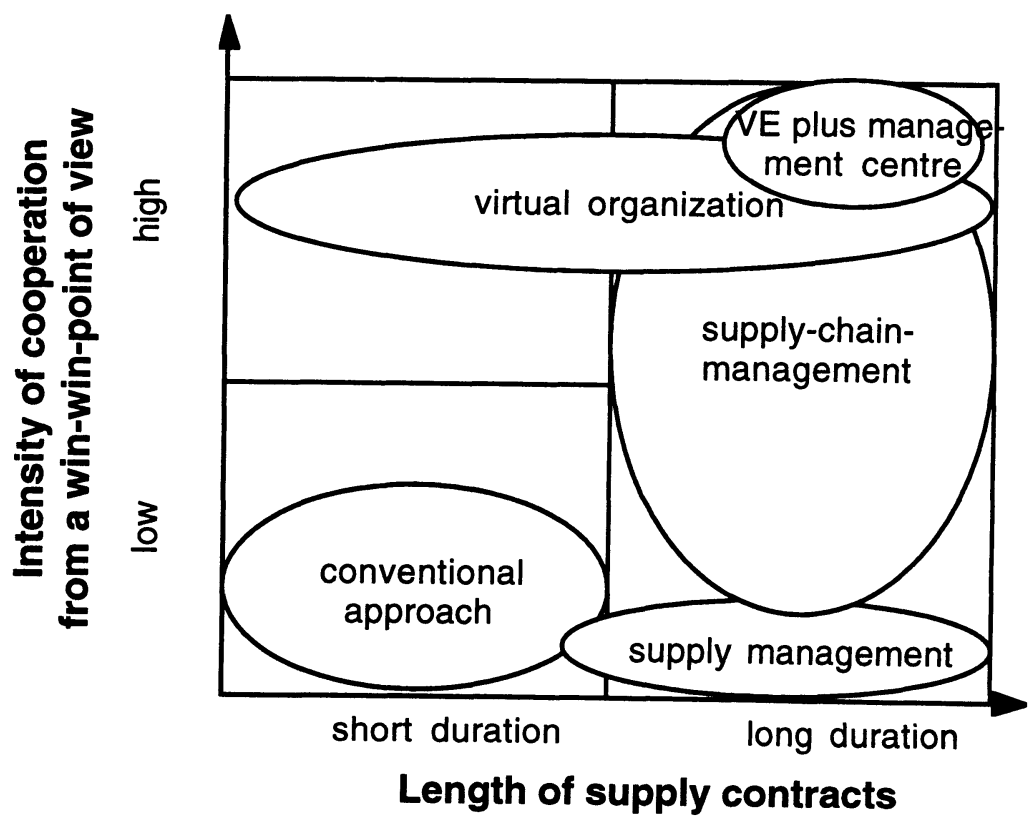

Figure 3: Intensity of cooperation (following [Schönsleben, 1997]) 
At the network's termination or reconfiguration stage, the service centre offers functional assistance in distributing profits or dividing losses, allocates joint resources and supports the network partners in marketing their goods and services. The staff of the service centre offers support for innovations when the network partners lack the necessary know-how. On demand, the service centre appoints one of the network partners or another service-providing company to do the servicing. Since marketing research is mainly carried out by the service centre's staff, its experts can tell what to do to quickly respond to the demands they discovered.

An essential service of the management centre is to support potential network partners in entering new markets or in attending to new customers. In doing this, it makes use of its previous experience from a variety of different cooperation projects. It avails itself of well-established infrastructural bodies and exploits their services and their practical experience with external institutions, like research institutes and consulting agencies, government facilities and chambers of commerce.

\section{CASE STUDY: INTERNATIONAL MODULAR UNIT SUPPLY IN THE AUTOMOTIVE INDUSTRY}

According to a Delphi study, $80 \%$ of the companies questioned foresee a strong increase in complex, modular units [Delphi-Studie, 1997]. Modular Sourcing enables cost advantages due to synergetic effects and allows to cut back on complexity and handling costs in purchasing. Moreover, it facilitates to build up close partnerships and catch up with the know-how edge of the suppliers. In Germany the trend goes towards a greater division of labour between supplier and customer. Already now $60 \%$ of German suppliers are increasingly taking on tasks of their customers.

IPA was asked by a German automotive supplier to plan and organise the assembling of a front-end module abroad. For a start, the product structure was defined and - in close co-ordination with the automobile manufacturer - the composition of the modular units was determined. Then, the assembly steps, the mounting devices and the buffer were defined. A cost-benefit-analysis, a feasibility study and a cost estimate for the module followed. In addition, the complete layout of the assembly plant was drafted and the supply chain of the purchase parts planned. By means of checklists and certificates of network suitability IPA supported the selection of cooperation partners. The cooperation process was optimised through a targeted interface management. From a neutral standpoint, IPA prepared and helped in the decision where to locate the assembly plant. Thanks to its good relations to national and international organisations IPA was able to provide for an excellent market entry of the automotive supplier.

Leaving the tasks of factory planning and logistics mainly in the hands of IPA, the automotive supplier could turn to its core business. And it could profit from IPA's thorough knowledge of the automobile industry, which gave it a competitive edge over its immediate competitors. In addition, IPA offered qualified help in 
defining the requirements on an information and communication network among the network partners.

In a next step, modern communication systems will have to be installed, such as e-mail, video conferences or other groupware, in order to co-ordinate the network partners. Likewise, project management systems or data and document systems are required. To this end "virtual filing cabinets" are established on the World Wide Web which are accessible to all partners. Prototypical organisation tools are currently being developed and will soon be put to practice. They allow to map and visualise the structure of a VE with its partners and their operating systems, interfaces, link-ups and conversion rules.

During the execution stage of the VE's life cycle several IT-systems are needed to support control and realisation of network tasks. In this context, research activities have been launched for a calculation software based on target pricing. Workflow management systems (WMS), as well as electronic organisation manuals and management information systems are already being used in other areas. A supra-plant PPC-system covering the manufacturing processes in several companies would be most welcome. Also necessary are a careful implementation and a continuous systems maintenance to adapt existing or future systems to the requirements of the networks. This is the task of the IT-experts in a management centre, who are also in a position to obtain attractive start-up bargains for the network partners due to the large number of projects for which they are responsible. Likewise, the staff of a qualified service centre can define requirement specifications and persuade the software producers into modifications so that standards emerge matching the needs of the network partners ideally.

\section{CASE STUDY: THE VIRTUAL FRAUNHOFER INSTITUTE FOR SIMULATION TECHNOLOGY (VFHI)}

The VFhI is a virtual union of several institutes of the Fraunhofer Society. They are all concerned with simulation and can fully exploit the facilities and competencies of the Fraunhofer umbrella organisation. The VFhI was established as the heart of a competence network which activates its individual "nodal points" according to need. Thus, it is possible to render services which a single institute could not provide as quickly, systematically, and in such a holistic and qualified manner.

The core competencies of the VFhI are

- Competence broker: The VFhI knows the specific expertise and tools of the individual institutes and also a great number of external competence providers. The VFhI is able to identify, bring together and use these competencies synergetically.

- Network management: The VFhI files the services that were previously rendered and enables a comparison of similar service and projects. The VFhI takes on the management of a knowledge and tools library and offers benchmarking and consulting services. 
- Integration platform: Apart from managing simulation services the VFhI takes care of all complementary and additional tasks. To this end, tools and knowhow for value added services derived from simulation technology are available, such as computer graphics, production planning and control, statistics, facility management, factory planning, CAD, etc. To make these services more effective an integration platform was developed which allows to handle easily those integrated services.

\section{OUTLOOK: INITIATIVE FOR SME COOPERATIONS IN THE STATE BADEN-WUERTTEMBERG (KIM BAWU)}

IPA plans a research project joining together more than 25 SMEs to realise a statewide cooperation marketplace for virtual enterprises.

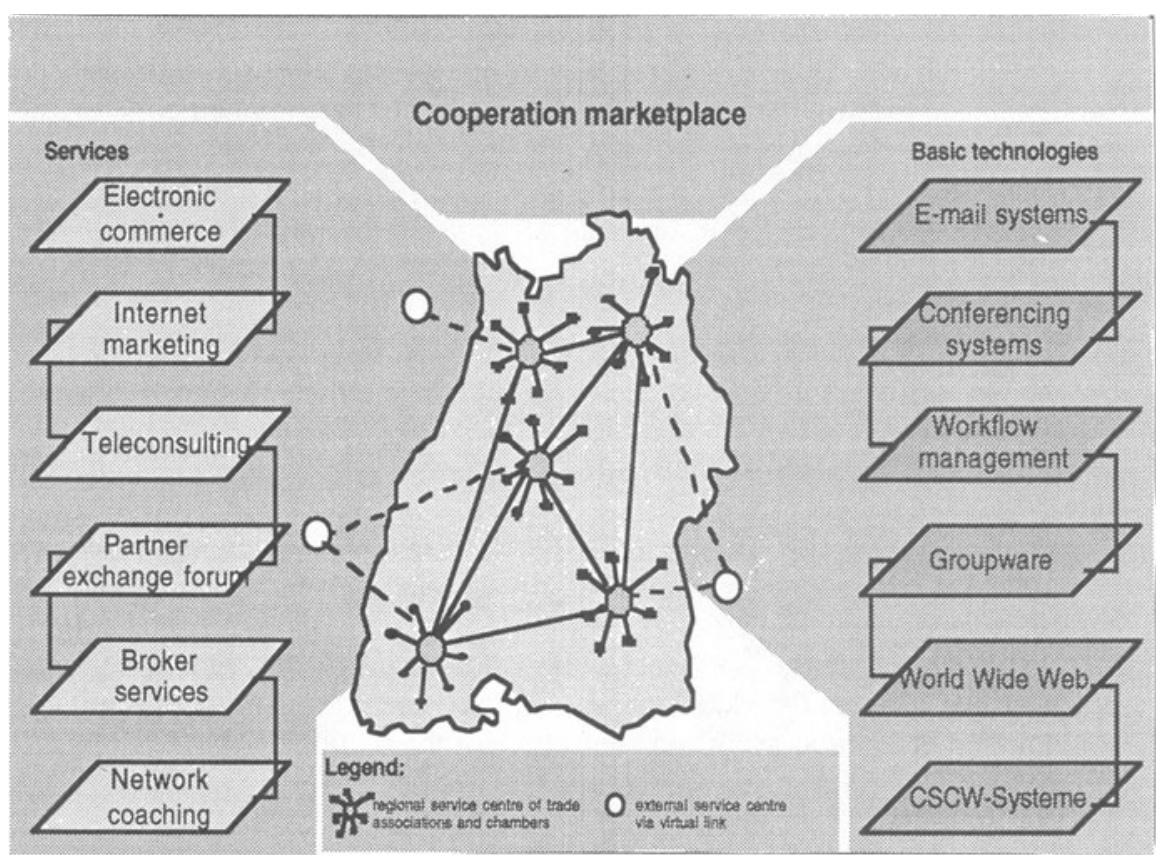

Figure 4: $\quad$ Cooperation marketplace

The experience and knowledge gained in this project will be available for interested enterprises through a service architecture enabling an interactive cooperation support. The development and implementation of this service architecture is the main target of the joint project. The intention is to design a concept to tele-consult VE-cooperations and to realise it as a pilot service centre. This service centre is a platform to support cooperation projects, offering on the one hand consulting services for company networks (active telebroker) and, on the 
other, provides for an "information warehouse" (passive telebroker) which unites methods, resources, information and IT-solutions for planning and operating company cooperations and combines them to an integrated overall service. To put such a comprehensive package of teleconsulting services into practice the following $R \& D$ activities are necessary:

- Realisation of an "information warehouse" combining practical experiences of company networks and individual know-how about methods, approaches and resources in order to build up, operate and dissolve company cooperations. This knowledge is gathered, managed and made accessible for companies via an internet exchange forum.

- Development and realisation of an electronic marketplace for cooperation partners (partner exchange forum). Here, companies searching for partners or offering their cooperation are able to get into contact. Companies participating in the partner exchange forum are being audited with regard to their organisational structure, operations, products and services.

- Development of broker services by means of modern information and communication technology. A service package has to be compiled covering all life cycle stages of a company network.

- Design of an information and communication platform to support cooperations and to enable broker services using state-of-the-art web technology.

The contents of the research activities are defined as follows:

- Design of a model architecture for virtual cooperations in the supplying industry: development of inter-company business processes, introduction of supra-plant team structures, implementation of information and communication networks.

- Electronic Business for international customer and project management in corporate networks: development of organisational concepts for international cooperations, design of tele-cooperation concepts to build up and operate international networks, implementation of internet/intranet-based project management systems for global engineering services, development of suitable solutions for order processing and controlling of international networks.

- Customer-oriented integration of distributed core competencies into marketable holistic solutions in virtual networks: building virtual links between cooperation partners, checking and selecting potential partners, prototyping and assessment of cooperation networks, inter-company integration of operational functions such as inventory management or invoicing, development of internet applications for order control.

\section{CONCLUSION}

Depending on the project definition, a service centre for virtual enterprises fulfils specific tasks required in a network. Its core competencies can be useful to all sorts 
of enterprises aiming to build a network. It offers a range of services a single company could never provide - if only because the acquisition of such a store of knowledge and experience would take too long. A company approaching the service centre with a specific task will benefit from the synergetic effects associated with a management centre that are due to its previous network projects in different markets. On the whole, the service centre supports and assists small and medium-sized enterprises in all life cycle stages with all difficult subjects.

\section{REFERENCES}

Heinze, H. (1997) Ein virtuell-flexibles Zuliefermodell: neue Positionen für Automobilzulieferunternehmen. Europäische Hochschulschriften: Reihe 5, Volks- und Betriebswirtschaft, Vol. 213 (Lang (Ed.)). Frankfurt am Main.

Mertens, P. (1996) Virtuelle Unternehmen. Eine Organisationsstruktur für die Zukunft? Wirtschaftswissenschaftliches Studium. Vol. 6/1996, pp. 280-285.

Mertens, P. and Faisst, W. (1997) Virtuelle Unternehmen: Idee, Informationsverarbeitung, Illusion. 18. Saarbrücker Arbeitstagung für Industrie, Dienstleistung und Verwaltung 1997. Universität des Saarlandes, Saarbrücken.

Rilling, G. (1997) Koordination im Produktionsverbund - Eine empirische Untersuchung. Gabler Edition Wissenschaft, Dt. Univ.-Verl, Wiesbaden.

Schönsleben, P. (1997) Von traditionellen Kunden-Lieferanten-Beziehungen hin zu partnerschaftlichen Konzepten der Zukunft. 2. IIR Produktionskongreß UP '97. Wiesbaden.

Sihn, W. (1995) Maintenance Concepts in the Fractal Factory. Proceedings of the 5th International FAIM Conference (R.D. Schraft, et al. (Ed.)), pp. 663-676. Begell House, New York.

Warnecke, H.J. (1993) The Fractal Company, A Revolution in Corporate Culture. Springer-Verlag. Berlin, Heidelberg, New York.

Weber, J. (1995) Modulare Organisationsstrukturen internationaler Unternehmensnetzwerke - Eine empirische Untersuchung. Gabler Edition Wissenschaft, Dt. Univ.-Verl., Wiesbaden.

Well, B. (1996) Ressourcenmanagement in strategischen Netzwerken. Das neue strategische Management (Hinterhuber, H. et al. (Ed.)). Gabler, Wiesbaden.

Wildemann, Horst (1997). Delphi-Studie. Unternehmensnetzwerke in der Zulieferindustrie. 
Wildemann, Horst (1997). Koordination von Unternehmensnetzwerken, Zeitschrift für Betriebswirtschaft. Vol 4/ 1997, pp. 417-439.

\section{BIOGRAPHY}

Engelbert Westkämper, Prof. Dr.-Ing. Dr. h.c., since 1995 Director of the Institut für Fabrikbetrieb und Industrielle Fertigung (IFF) and Professor at the University Stuttgart and Managing Director of the Fraunhofer-Institut für Produktionstechnik und Automatisierung (IPA) in Stuttgart, Germany, born in 1946, graduated in 1977 from the RWTH Aachen on the planning of flexible automated manufacturing systems. Before rejoining university in 1988 as Director of the Institut für Werkzeugmaschinen und Fertigungstechnik (IWF) and Professor at the Technische Universität Braunschweig, Germany, he had been working for 12 years in the German aircraft (MBB) and electronics industry where he was responsible for the development, planning and introduction of new manufacturing methods and technologies, finally as Director and Head of the central department "Production Engineering" of AEG AG Frankfurt. He was envolved in numerous projects of development and applications of new manufacturing technologies and concepts.

Dipl.-Ing. Dipl. Wirt.-Ing. Hans-Jörg Tutsch has been a member of the Fraunhofer Institute for Manufacturing Engineering and Automation (IPA) since 1996. He is working as a research engineer in the Enterprise Logistics Department with a focus of his work on Virtual Enterprises and Supply Chain Management. 